\title{
ANALYSIS OF KeY CONSIDERATIONS OF THE Public When Choosing Recreational ACTIVITIES
}

\author{
Han-Chen Huang ${ }^{1}$, Chun-Ta Lin ${ }^{2 *}$, Chi-Han Chuang ${ }^{3}$ \\ ${ }^{1}$ Department of Tourism and MICE, Chung Hua University, Taiwan \\ ${ }^{2 *}$ Corresponding Author Department of Information Management, Yu Da University of Science \\ and Technology, Taiwan \\ ${ }^{3}$ Department of Information Management, Yu Da University of Science and Technology, \\ Taiwan \\ ${ }^{3}$ Da-Tung Elementary School, Miaoli County, Taiwan
}

\begin{abstract}
This study aims to investigate the key considerations of the public when choosing recreational activities, and concludes the key factors to be considered when choosing recreational activities, as well as the influence of various factors by means of literature review, expert interview, questionnaire survey, and Analytical Hierarchy Process (AHP). Through analysis, this study identified 12 influential factors for selecting recreational activities, among which the most important 6 influential factors are improving physical ability, body building, pressure relief, traffic convenience, cost, and comfort of exercise environment, at $77.6 \%$.
\end{abstract}

\section{KEYWORDS}

Recreational activities, Analytical Hierarchy Process, Influence.

\section{INTRODUCTION}

Many studies, of both scientific and medical circles, have pointed out the benefits of recreational activities [1-3]. Many medical and scientific reports indicate that activity and exercise are methods to promote health and prevent disease, and suggest fostering the habits of regular activities and exercising for at least 30 minutes every day [4]. Recreational activities not only promote physical health, but also have the functions of promoting mental health development, can be attached with the pursuit of pleasure, and achieve the effect of social activities.

Recreational activities have complex and diverse classifications, as well as different classification standards due to different research purposes of scholars, changing times, and the influence of many relevant factors, such as social evolution. In Taiwan, Hsieh and Jeng [5] divided recreational activities into recreation activities related to media, culture, exercise, social needs, outdoor activities, and hobbies. Hung [6] divided recreational activities into recreation activities related to ball exercises, leisure, tourism, the art of attack and defense, activities above water and in water, entertainment, art, physical fitness, and breathtaking activities. Hsieh and Jeng [7] divided recreational activities into recreation activities related to the art of attack and defense, recreation, tourism, recreational activities, consumption, team, water and art, static activities, football activities for two people, etc. People are engaged in a variety of recreational activities, 
but aim to pursue nothing more than health, achievements, knowledge accumulation, social relations, stimulating body and mind, physical exercise, killing time, pressure relief, etc.[5-8]. However, the considerations of people for when choosing recreational activities remains in question; therefore, the research purposes are as follows:

- To clarify the factors to be considered when choosing recreational activities.

- To analyze the influence of various factors to be considered when choosing recreational activities.

\section{LITERATURE REVIEW}

\subsection{Recreational activities}

Over time, Taiwanese people have changed their lifestyles, with more concerns on health and exercise. Taiwan's government has invested hundreds of millions of dollars in promoting exercise and leisure every year in order to promote health and improve quality of life. The public have become more involved recreational activities, which can have positive influence on their physiology and psychology [9].

\subsubsection{Physiology}

- Achieving the effect of weight loss by burning calories and reducing appetite.

- Reducing the risk of diabetes.

- Improving their physical fitness.

- Regular exercise helps to effectively reduce blood pressure.

\subsubsection{Psychology}

- Promoting excitement and pleasant feelings: Studies of psychologists and sociologists show that exercise has certain curative effects on depression. Studies also show that a chemical substance, known as beta-endorphin, will be improved within the nervous system during exercise, which allows people to have excited and pleasant feelings and promote positive thinking.

- Pressure relief: Recreational activities help to reduce the pressure of the circulatory system of the body, promote physical health, and have the function of promoting mental health.

\subsection{Delphi method}

The Delphi method is a decision-making method, where the problems of an issue are sent to experts to consult their opinions, which are then collected and summarized in order to conclude comprehensive opinions, and these comprehensive opinions are returned to the experts in order that all experts can change their original opinions on the basis of a set of comprehensive opinions, and summarize their opinions, thus, gradually achieving consistent results after such repeated steps. This method is widely representative, as such investigation allows neither direct discussions among experts, nor transverse association, and through repeated consulting, summary, and modification, finally concludes the basic consistent views of the experts [10-12].

\subsection{AHP}

AHP (Analytical Hierarchy Process) was developed by Thomas L. Saaty at the University of 
Pittsburgh in 1971, but it was not perfected until after 1980 [13, 14]. AHP aims to solve problems that are very complex and require the consideration of too many influential factors, meaning it is a decision-making method with multiple assessment criteria developed under uncertain circumstances [15].

AHP systematically breaks down problems, hierarchizes the problems, then determines the ratio of relative importance between factors through the pairwise comparison method, and arranges the option sequence, which becomes the basis for selecting the best option. It aims to systematize complex problems, collect related information through a logical and hierarchical structure, and make decisions and evaluations according to ideas and intuitive judgment. For policy makers, the hierarchical structure helps to understand issues, cut complex and unstructured situations into a number of components, set up the hierarchical order, determine the importance of each variable in accordance with the subjective judgment, and determine the priority of each variable after a series of judgments and statistics, thus, helping decision makers to reach conclusions[16-19].

\section{RESEARCH METHOD}

\subsection{Establish a hierarchical structure}

In order to investigate the factors considered by the public, and choose recreational activities and the degrees of importance of various factors, this study first identified the factors based on existing literature, selected the factors that affect the choice of recreational activities, and constructed the preliminary hierarchical structure. An effective and complete hierarchical structure was established after repeated analyses on the preliminary hierarchical structure by Delphi questionnaire survey, until expert consensus was reached.

The Delphi questionnaire survey is based on the consensus of experts and scholars; however, during its process, the response rate of the survey tends to decline with the increased number of times it is repeated. Therefore, this study conducted two rounds of Delphi questionnaire survey. The process is as shown in Table 1:

Table 1. Implementation process of Delphi questionnaire

\begin{tabular}{lll}
\hline \multicolumn{1}{c}{ Times } & \multicolumn{1}{c}{ Content } \\
\hline Lead time & $\begin{array}{l}\text { The experts were invited to take the questionnaire survey, and their } \\
\text { agreement with the research proposal was obtained. }\end{array}$ \\
\hline $\begin{array}{l}\text { First questionnaire } \\
\text { survey on April 15, } \\
2014\end{array}$ & $-\begin{array}{l}\text { The experts received the first invitation letter and first round of } \\
\text { questionnaire. }\end{array}$ \\
\hline $\begin{array}{l}\text { Delphi experts filled out the questionnaire. } \\
\text { questionnaire survey on } \\
\text { July 25, 2014 }\end{array}$ & $-\begin{array}{l}\text { The experts received the second invitation letter and second } \\
\text { questionnaire of Delphi experts, along with the answer records } \\
\text { and analysis results of the first questionnaire. } \\
\text { The experts filled out the questionnaire, summarized the results, } \\
\text { and conducted reliability test of the questionnaire results. }\end{array}$ \\
\hline
\end{tabular}

After the second Delphi questionnaire survey, the questionnaire was modified according to the experts' opinions to reach their consensus, and the hierarchical structure of key factors in choosing recreational activities was then constructed (Tables 2 and 3). There are three hierarchical structures: 1) the key factors considered for choosing recreational activities; 2) the influential factors, including physical health, psychology, social climate, place, and cost; 3) the 
International Journal of Computer Science \& Information Technology (IJCSIT) Vol 7, No 1, February 2015

influential factors, including 12 factors. The hierarchical structure is as shown in Figure 1.

Table 2. Delphi questionnaire survey results (1)

\begin{tabular}{ccc}
\hline Influential factors & $\begin{array}{c}\text { First Delphi questionnaire } \\
\text { results }\end{array}$ & $\begin{array}{c}\text { Second Delphi questionnaire } \\
\text { results }\end{array}$ \\
\hline Internal personal factors & Personal health & Physical health \\
\hline External factors & Personal psychology & Psychology \\
\hline Physical health & Social factors & Social climate \\
\hline Psychology & Environmental factors & Place and cost \\
\hline Interest & Cost factors & \\
\hline Society & & \\
\hline Environment & & \\
\hline Cost & & \\
\hline
\end{tabular}

Table 3. Delphi questionnaire survey results (2)

\begin{tabular}{|c|c|c|}
\hline Influential factors & $\begin{array}{l}\text { First Delphi questionnaire } \\
\text { results }\end{array}$ & $\begin{array}{c}\text { Second Delphi questionnaire } \\
\text { results }\end{array}$ \\
\hline Increase physical fitness & Increase physical ability & Improving the physical ability \\
\hline Exercise injury & Exercise injury & Body building \\
\hline Body building effect & Body building effect & Technical difficulties of exercise \\
\hline $\begin{array}{l}\text { Increase the ability to protect } \\
\text { physical health }\end{array}$ & $\begin{array}{c}\text { Years of being involved in } \\
\text { exercise items }\end{array}$ & Self-challenge \\
\hline Years of exercise & Technology and difficulty & Pressure relief \\
\hline Self-realization & Self-challenge & Interest \\
\hline Pressure relief & Pressure relief & Social needs \\
\hline Interest and abundance & Interest & Joint activities of family \\
\hline Technical advancement & Family and social needs & Social popularity \\
\hline Probability of becoming hobby & Social popularity & $\begin{array}{c}\text { Comfort level of the exercise } \\
\text { environment }\end{array}$ \\
\hline Breathtaking and challenging & Government driving & Traffic convenience \\
\hline Involved in exercise teams & Place requirements & Cost \\
\hline Social needs & $\begin{array}{c}\text { Comfort level of the exercise } \\
\text { environment }\end{array}$ & \\
\hline Family and parent-child & Traffic convenience & \\
\hline Social popularity & $\begin{array}{c}\text { Limit of number of people in } \\
\text { exercise items }\end{array}$ & \\
\hline Traffic convenience & Cost of facilities & \\
\hline Exercise environment and space & Place cost & \\
\hline \multicolumn{3}{|l|}{ Place getting difficulty } \\
\hline \multicolumn{3}{|l|}{$\begin{array}{c}\text { Limit of number of people in } \\
\text { exercise items }\end{array}$} \\
\hline \multicolumn{3}{|l|}{ Cost of facilities } \\
\hline Place cost & & \\
\hline
\end{tabular}




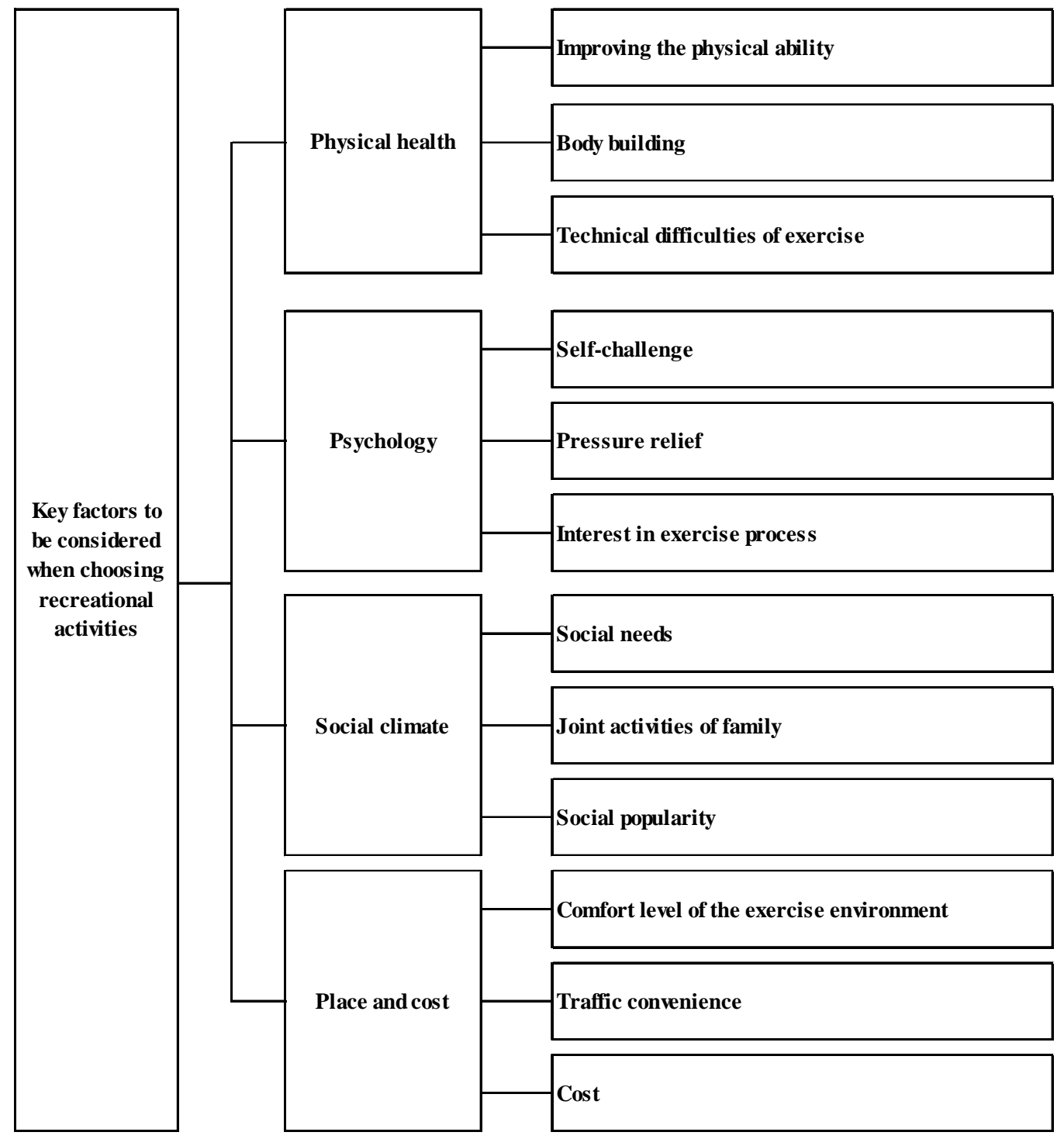

Figure 1. Hierarchical structure of key factors to be considered when choosing recreational activities

\subsection{Analytic hierarchy process (AHP)}

AHP uses a nominal scale, rather than a physical scale. The scale includes: equal importance, moderate importance, essential importance, very strong importance, and extreme importance, as well as four scales between each two (Table 4). Based on the suggestions of Saaty and Vargas [19], the AHP questionnaire was designed to be easily comprehensible and able to show comparison. In addition, the content description could guide the respondents to compare two factors. 
Table 4. Definitions and descriptions of the evaluation scale [13, 14]

\begin{tabular}{ccl}
\hline Evaluation scale & Definition & \multicolumn{1}{c}{ Description } \\
\hline 1 & Equal importance & $\begin{array}{l}\text { The contributions of two schemes to be } \\
\text { compared have equal importance }\end{array}$ \\
\hline 3 & Weak importance & $\begin{array}{l}\text { Experience and judgment tends to slightly } \\
\text { favor a scheme }\end{array}$ \\
\hline 5 & Essential importance & $\begin{array}{l}\text { Experience and judgment tends to strongly } \\
\text { favor a scheme }\end{array}$ \\
\hline 9 & Extremely strong importance & $\begin{array}{l}\text { Practice shows a very strong tendency to } \\
\text { favor a scheme }\end{array}$ \\
\hline $2,4,6,8$ & Absolute importance & $\begin{array}{l}\text { Enough evidence affirms to absolutely favor } \\
\text { a scheme }\end{array}$ \\
\hline
\end{tabular}

AHP first establishes a hierarchical structure, then collects the objective opinions of experts, breaks down and simplifies complex problems from the top down, and quantifies choice orientations difficult to present, in order to have a clear understanding, easily appraise priority through comparison, improve decision quality, and be closer to the factors affecting the key points for the public to choose recreational activities. Pairwise comparison steps in AHP criterion are, as follows [13-21]:

1) Establish a pairwise comparison matrix:

Suppose that there are factors $A_{1}, A_{2}, A_{3}, A_{4}, \ldots \ldots A_{n}$ in a hierarchy, the weight of each factor is $W_{1}, W_{2}, W_{3}, \ldots \ldots W_{n}$, and then a pairwise comparison matrix is established accordingly, where the relative importance of any two items $A_{i}$ and $A_{j}$ is expressed as $a_{i_{j}}$, and the pairwise comparison matrix of factors $W_{n}, A_{1}, A_{2}, A_{3}, A_{4}, \ldots \ldots A_{n}$ is $\mathrm{A}=\left\lfloor a_{i_{j}}\right\rfloor$. If weights $W_{1}, W_{2}, W_{3}, \ldots \ldots W_{n}$ are known, then the pairwise comparison matrix $\mathrm{A}=\left\lfloor a_{i_{j}}\right\rfloor$ can be expressed as Eq. 1.

$$
\mathrm{A}=\left[a_{i_{j}}\right]=\left[\begin{array}{cccc}
W_{1} / W_{1} & W_{1} / W_{2} & \ldots & W_{1} / W n \\
W_{2} / W_{1} & W_{2} / W_{2} & \ldots & W_{2} / W_{n} \\
\cdot & \cdot & \ldots & \cdot \\
W_{n} / W_{1} & W_{n} / W_{2} & \ldots & W_{n} / W_{n}
\end{array}\right]
$$

where $a_{i j}=W_{i} / W_{j}, a_{i j}=W_{j} / W_{i}, \mathrm{i}, \mathrm{j}=1,2, \ldots \ldots, \mathrm{n}$

2) Calculate the maximum eigenvector and eigenvalue:

Based on the pairwise comparison matrix, it is possible to calculate the eigenvector corresponding to the maximum eigenvalue (known as the advantageous vector and weight distribution). The pairwise comparison matrix A multiplied by vector $\bar{W}$ consists of the weights of various criteria, and can be expressed as Eq. 2:

$$
\bar{W}=\left(W_{1}, W_{2}, W_{3}, \ldots \ldots W_{n}\right)^{T}
$$




$$
\mathrm{A} \bar{W}=\left[\begin{array}{cccc}
W_{1} / W_{1} & W_{1} / W_{2} & \ldots & W_{1} / W_{n} \\
W_{2} / W_{1} & W_{2} / W_{2} & \ldots & W_{2} / W_{n} \\
\cdot & \cdot & \ldots & \cdot \\
W_{n} / W_{1} & W_{n} / W_{2} & \ldots & W_{n} / W_{n}
\end{array}\right]\left[\begin{array}{c}
W_{1} \\
W_{2} \\
\cdot \\
W_{n}
\end{array}\right]=\lambda\left[\begin{array}{c}
W_{1} \\
W_{2} \\
\cdot \\
W_{n}
\end{array}\right]
$$

Eq. 2 shows that, the pairwise comparison matrix A multiplied by $\bar{W}$ is equal to the value of $\lambda$ multiplied by $\bar{W}$; namely $\mathrm{A} \bar{W}=\lambda \bar{W} . \lambda$ is the eigenvalue of $\mathrm{A}$, and is the eigenvector of the pairwise matrix A corresponding to the eigenvalue.

In practical pairwise comparison, $a_{i j}$ is obtained through subjective judgment; therefore, it must have a certain gap with the practical $W_{i} / W_{j}$, and becomes $a_{i j} \approx W_{i} / W_{j}$. When $a_{i_{j}}$ has small changes, the eigenvalue will change accordingly. When the eigenvalue is no longer equal to $\lambda, \lambda$ is still the main eignenvalue, and is very close to the eigenvalue of the theoretical weight. Namely, $\lambda$ is replaced with $\lambda \max$, as shown in Eq. 3 .

$$
\mathrm{A} \bar{W}=\lambda \max \times \bar{W}
$$

The steps of calculating the maximum eigenvalue $\lambda \max$ are, as follows. A new vector $\bar{W}^{\prime}$ will be obtained through multiplying the pairwise comparison matrix A by the obtained eigenvector $\bar{W}^{\prime}$, as shown in Eqs. 4 and 5.

$$
\begin{gathered}
\mathrm{A} \bar{W}=\bar{W}^{\prime} \\
{\left[\begin{array}{cccc}
W_{1} / W_{1} & W_{1} / W_{2} & \ldots & W_{1} / W_{n} \\
W_{2} / W_{1} & W_{2} / W_{2} & \ldots & W_{2} / W_{n} \\
\cdot & \cdot & \ldots & \cdot \\
W_{n} / W_{1} & W_{n} / W_{2} & \ldots & W_{n} / W_{n}
\end{array}\right]\left[\begin{array}{c}
W_{1} \\
W_{2} \\
\cdot \\
W_{n}
\end{array}\right]=\left[\begin{array}{c}
W_{1^{\prime}} \\
W_{2^{\prime}} \\
\cdot \\
W_{n^{\prime}}
\end{array}\right]}
\end{gathered}
$$

$\lambda$ max can be obtained by dividing each known vector value by each of the original values, and then calculating the arithmetic average of all obtained quotients, as shown in Eq. 6.

$$
\lambda \max =\frac{1}{n}\left(\frac{W_{1}}{W_{1}}+\frac{W_{2}}{W_{2}}+\ldots .+\frac{W_{n}^{\prime}}{W_{n}}\right)
$$

\section{3) Consistency tests:}

It is difficult to request that respondents achieve consistency in pairwise comparison, thus, consistency tests are required to obtain a consistency index (C.I.) (Eq. 7) in order to check whether the pairwise comparison matrix consisting of respondents' answers is a consistency matrix. Saaty [15] suggested that, C.I. $=0$ denotes complete consistency of the evaluators' judgment, where C.I. $\leq 0.1$ is an acceptable error value, thus, ensuring consistency.

$$
\text { C.I. }=\frac{\lambda \max -\lambda}{n-1}
$$


A positive reciprocal matrix is obtained from the assessment scale of 1 to 9 , and the C.I. under different number of hierarchies is a random index (R.I.). In a matrix with the same number of hierarchies, the ratio of C.I. to R.I. is known as the C.R. (consistency ratio, Eq. 8). Saaty [15] suggested that C.R. $\leq 0.1$ means that consistency reaches an acceptable level.

$$
\text { C.R. }=\frac{\text { C.I. }}{\text { R.I. }}
$$

\section{RESULTS AND DISCUSSION}

\subsection{Consistency tests}

In the pairwise comparison, AHP must meet the transitivity between quality relationship and strength relationship. However, in the actual process, as it is difficult to avoid errors caused by some factors, consistency tests are necessary; therefore, Satty suggested checking the consistency of the pairwise comparison matrix with the consistence ratio (C.R.). This study investigated the experts of recreational activities in Taiwan, including 6 physical education teachers, 5 members of recreational activities organizations, and 4 recreational activities promoters. This study distributed 15 questionnaires, and recovered 13 samples. After eliminating 4 invalid samples, there were 9 valid samples. Table 5 shows the consistency tests results, all of which meet the standard of C.I. $<=0.1$ and C.R. $<=0.1$, as proposed by Satty[19].

Table 5. Consistency tests results

\begin{tabular}{|c|c|c|c|c|c|c|}
\hline $\begin{array}{c}\text { First } \\
\text { hierarchy }\end{array}$ & & & & $\begin{array}{c}\text { Third } \\
\text { hierarchy }\end{array}$ & & \\
\hline Goal & $\begin{array}{l}\text { Influential } \\
\text { factors }\end{array}$ & C.I. & C.R. & Influential factors & C.I. & C.R. \\
\hline \multirow{4}{*}{$\begin{array}{l}\text { Key factors } \\
\text { to be } \\
\text { considered } \\
\text { when } \\
\text { choosing } \\
\text { recreational } \\
\text { activities }\end{array}$} & Physical health & \multirow{4}{*}{0.0703} & \multirow{4}{*}{0.0781} & $\begin{array}{l}\text { Improving the physical ability } \\
\text { Body building } \\
\text { Technical difficulties of exercise }\end{array}$ & 0.0369 & 0.0636 \\
\hline & Psychology & & & $\begin{array}{l}\text { Self-challenge } \\
\text { Pressure relief } \\
\text { Interest in exercise process }\end{array}$ & 0.0401 & 0.0692 \\
\hline & Social climate & & & $\begin{array}{l}\text { Social needs } \\
\text { Joint activities of family } \\
\text { Social popularity }\end{array}$ & 0.0002 & 0.0003 \\
\hline & Place and cost & & & $\begin{array}{l}\text { Comfort level of the exercise } \\
\text { environment } \\
\text { Traffic convenience } \\
\text { Cost }\end{array}$ & 0.0015 & 0.0026 \\
\hline
\end{tabular}




\subsection{Results Analysis}

\subsubsection{Weight value of the influential factor hierarchy and its order}

As can be seen from the pairwise comparison matrix and weights of the 4 influential factors, as shown in Tables 6 and 7, the influences of the 4 factors are ranked in descending order: physical health (0.478), place and cost (0.268), psychology (0.185), and social climate $(0.069)$. The results show that the public choose recreational activities after primary considerations of promoting physical health and physical beauty, the influence of which is as high as $47.8 \%$, the secondary consideration of place and cost, the influence of which is as high as $26.8 \%$, and tertiary consideration of pressure relief, the influence of which is as high as $18.5 \%$, while the influence of social climate on choosing recreational activities by the people is only $6.9 \%$.

Table 6. Pairwise comparison matrix of the influential factor hierarchy

\begin{tabular}{ccccc}
\hline & Physical health & Psychology & Social climate & Place and cost \\
\hline Physical health & 1.000 & 4.429 & 4.857 & 1.571 \\
\hline Psychology & 0.226 & 1.000 & 3.286 & 0.905 \\
\hline Social climate & 0.206 & 0.304 & 1.000 & 0.219 \\
\hline Place and cost & 0.636 & 1.105 & 4.566 & 1.000 \\
\hline
\end{tabular}

Table 7.Weight values of the influential factor hierarchy

\begin{tabular}{lccccc}
\hline & Physical health & Psychology & Social climate & Place and cost & Weights \\
\hline Physical health & 0.484 & 0.648 & 0.354 & 0.425 & 0.478 \\
\hline Psychology & 0.109 & 0.146 & 0.240 & 0.245 & 0.185 \\
\hline Social climate & 0.100 & 0.045 & 0.073 & 0.059 & 0.069 \\
\hline Place and cost & 0.308 & 0.162 & 0.333 & 0.271 & 0.268 \\
\hline
\end{tabular}

\subsubsection{Weight values of the influential factor hierarchy, and its order}

(1)Influential factor: physical health

As can be seen from the pairwise comparison matrix and weight analysis of Tables 8 and 9, the importance of 3 influential factors is ranked in descending order; improving physical ability (0.482), body building (0.344), and technical difficulties of exercise (0.174). Where, improving physical ability and body building are important factors to the public.

Table 8. Pairwise comparison matrix (influential factor: Physical health)

\begin{tabular}{cccc}
\hline & $\begin{array}{c}\text { Improving the physical } \\
\text { ability }\end{array}$ & Body building & $\begin{array}{c}\text { Technical difficulties of } \\
\text { exercise }\end{array}$ \\
\hline $\begin{array}{c}\text { Improving the physical } \\
\text { ability }\end{array}$ & 1.000 & 1.857 & 2.162 \\
\hline Body building & 0.538 & 1.000 & 2.619 \\
\hline $\begin{array}{c}\text { Technical difficulties of } \\
\text { exercise }\end{array}$ & 0.463 & 0.382 & 1.000 \\
\hline
\end{tabular}


Table 9. Result of weight analysis (influential factor: Physical health)

\begin{tabular}{ccccc}
\hline & $\begin{array}{c}\text { Improving the } \\
\text { physical ability }\end{array}$ & Body building & $\begin{array}{c}\text { Technical difficulties of } \\
\text { exercise }\end{array}$ & Weights \\
\hline $\begin{array}{c}\text { Improving the physical } \\
\text { ability }\end{array}$ & 0.500 & 0.573 & 0.374 & 0.482 \\
\hline Body building & 0.269 & 0.309 & 0.453 & 0.344 \\
\hline $\begin{array}{c}\text { Technical difficulties of } \\
\text { exercise }\end{array}$ & 0.231 & 0.118 & 0.173 & 0.174 \\
\hline
\end{tabular}

(2) Influential factor: psychology

As shown in Tables 10 and 11, the importance of 3 influential factors is ranked in descending order; pressure relief (0.613), interest in exercise process $(0.254)$, and self-challenge $(0.132)$. The weights of the three factors are greatly different, meaning pressure relief and interests are valued by the public, while the influence of self-challenge is only $13.2 \%$.

Table 10. Pairwise comparison matrix (influential factor: psychology)

\begin{tabular}{cccc}
\hline & Self-challenge & Pressure relief & Interest in exercise process \\
\hline Self-challenge & 1.000 & 0.276 & 0.390 \\
\hline Pressure relief & 3.623 & 1.000 & 3.286 \\
\hline Interest in exercise process & 2.562 & 0.304 & 1.000 \\
\hline
\end{tabular}

Table11. Result of weight analysis (influential factor: psychology)

\begin{tabular}{ccccc}
\hline & Self-challenge & Pressure relief & $\begin{array}{c}\text { Interest in } \\
\text { exercise process }\end{array}$ & Weights \\
\hline Self-challenge & 0.139 & 0.175 & 0.083 & 0.132 \\
\hline Pressure relief & 0.504 & 0.633 & 0.703 & 0.613 \\
\hline Interest in exercise process & 0.357 & 0.193 & 0.214 & 0.254 \\
\hline
\end{tabular}

(3) Social climate

According to Tables 12 and 13, the importance of 3 influential factors is ranked in descending order; joint activities of family (0.447), social needs $(0.341)$, and social popularity $(0.213)$. The weight of joint activities of a family is the highest, and its importance degree reaches $44.7 \%$, showing that the public attach great importance to joint family activities, followed by social needs, the importance degree of which also reaches $34.1 \%$, and social popularity has $21.3 \%$ influence on choosing recreational activities by the public.

Table 12. Pairwise comparison matrix (influential factor: social climate)

\begin{tabular}{cccc}
\hline & Social needs & $\begin{array}{c}\text { Joint activities of } \\
\text { family }\end{array}$ & Social popularity \\
\hline Social needs & 1.000 & 0.778 & 1.571 \\
\hline Joint activities of family & 1.286 & 1.000 & 2.143 \\
\hline
\end{tabular}


International Journal of Computer Science \& Information Technology (IJCSIT) Vol 7, No 1, February 2015

\begin{tabular}{ccccc}
\hline \multicolumn{2}{c}{0.636} & 0.467 & 1.000 \\
\hline \multicolumn{4}{c}{ Table 13. Result of weight analysis (influential factor: social climate) } \\
\hline Social needs & $\begin{array}{c}\text { Joint activities } \\
\text { of family }\end{array}$ & $\begin{array}{c}\text { Social } \\
\text { popularity }\end{array}$ & Weights \\
\hline Social needs & 0.342 & 0.346 & 0.333 & 0.341 \\
\hline Joint activities of family & 0.440 & 0.446 & 0.455 & 0.447 \\
\hline Social popularity & 0.218 & 0.208 & 0.212 & 0.213 \\
\hline
\end{tabular}

(4) Place and cost

As shown in Tables 14 and 15, the importance of 3 influential factors is ranked in descending order; comfort level of the exercise environment (0.339), traffic convenience $(0.339)$, and cost (0.321). The 3 influential factors have equal influence, with $32.1 \% \sim 33.9 \%$ influence on choosing recreational activities by the public.

Table 14. Pairwise comparison matrix (influential factor: place and cost)

\begin{tabular}{cccc}
\hline & $\begin{array}{c}\text { Comfort level of the } \\
\text { exercise environment }\end{array}$ & Traffic convenience & Cost \\
\hline $\begin{array}{c}\text { Comfort level of the } \\
\text { exercise environment }\end{array}$ & 1.000 & 1.000 & 0.896 \\
\hline Traffic convenience & 1.000 & 1.000 & 1.057 \\
\hline Cost & 1.116 & 0.946 & 1.000 \\
\hline
\end{tabular}

Table 15. Result of weight analysis (influential factor: place and cost)

\begin{tabular}{ccccc}
\hline & $\begin{array}{c}\text { Comfort level of the } \\
\text { exercise environment }\end{array}$ & $\begin{array}{c}\text { Traffic } \\
\text { convenience }\end{array}$ & Cost & Weights \\
\hline $\begin{array}{c}\text { Comfort level of the } \\
\text { exercise environment }\end{array}$ & 0.321 & 0.339 & 0.304 & 0.321 \\
\hline Traffic convenience & 0.321 & 0.339 & 0.358 & 0.339 \\
\hline Cost & 0.358 & 0.321 & 0.339 & 0.339 \\
\hline
\end{tabular}

\subsubsection{Overall weight values and their order}

The overall weights of the 12 influential factors can be obtained through calculation, and are ranked in descending order in Table 16, where the top 6 important influential factors are successively: improving physical ability $(0.230)$, body building (0.164), pressure relief $(0.113)$, traffic convenience (0.091), cost (0.091), and comfort of exercise environment (0.086). The total influence of which on choosing recreational activities by the public is more than $77.5 \%$; while that of the remaining 6 influential factors (technical difficulties of exercise, interests, joint activities of family, self-challenge, social needs, social popularity) is only $22.5 \%$. When choosing recreational activities, people first consider "improving physical ability", which accounts for $23 \%$ of the overall weight, followed by considering "body building" (importance degree 16.4\%), and "pressure relief" (importance degree 11.3\%). The influence of the three influential factors totals more than $50 \%$, showing that contemporary people attach the greatest importance to their physical health, pursuing physical beauty, and relieving mental pressure. The influence of 3 
International Journal of Computer Science \& Information Technology (IJCSIT) Vol 7, No 1, February 2015

factors (social popularity, social needs, self-challenge) on choosing recreational activities by the public is the lowest (only 6.3\%).

Table 16. Ranking of relative weights of influential factors on choosing recreational activities by the public

\begin{tabular}{ccc}
\hline Influential factors & Overall weight & Overall ranking \\
\hline Improving the physical ability & 0.230 & 1 \\
\hline Body building & 0.164 & 2 \\
\hline pressure relief & 0.113 & 3 \\
\hline Traffic convenience & 0.091 & 4 \\
\hline Cost & 0.091 & 5 \\
\hline Comfort level of the exercise environment & 0.086 & 6 \\
\hline Technical difficulties of exercise & 0.083 & 7 \\
\hline Interest in exercise process & 0.047 & 8 \\
\hline Joint activities of family & 0.031 & 10 \\
\hline self-challenge & 0.024 & 11 \\
\hline social needs & 0.024 & 12 \\
\hline social popularity & 0.015 & \\
\hline
\end{tabular}

\section{CONCLUSION}

This study identified 4 factors to be considered when choosing recreational activities: physical health, psychology, social climate, and place and cost. Twelve 12 key influential factors were determined: improving physical ability, body building effect, required technical difficulty of exercise, self-challenge, pressure relief, interest in exercise process, social needs, joint activities of family, social popularity, comfort of exercise environment, traffic convenience, and cost.

The results showed that, when choosing recreational activities, people first consider "improving physical ability"(importance degree 23\%), and then consider "body building" (importance degree $16.4 \%$ ) and "pressure relief"(importance degree 11.3\%). The influence of the three influential factors accounts for more than 50\%, showing that people attach the greatest importance to their physical health, pursuing physical beauty, and relieving mental pressure. Influence of the factors, such as social popularity, social needs, and self-challenge, on choosing recreational activities is extremely low (only 6.3\%).

\section{ACKNOWLEDGEMENTS}

This study was developed and planned by Dr. Han-Chen Huang and accomplished with the assistance of Chi-Han Chuang. Under the advices of Dr. Chun-Ta Lin, Chi-Han Chuang probed into this research topic and obtained the master's degree.

\section{REFERENCES}

[1] Aw, D.F., Wu, Y.Z., Huang, K.C., Huang, S.F., and Chen, Y.J., (2013) "The Influence of Regular Exercise Training on The Physical Status of Health Young People", Journal of Tzu Chi College of Technology, Vol. 21, No. 1, pp 89-100.

[2] Matej, T., Eva, K., Suzana, T., and Robert, M., (2012) "Sport, Health and Work Efficiency in 
International Journal of Computer Science \& Information Technology (IJCSIT) Vol 7, No 1, February 2015

Slovenian Armed Forces", Research in Physical Education, Sport and Health, Vol. 1, No. 1, pp 33-38.

[3] Ardahan, F., (2013) "The Relation Between Neighboring, Tolerance of Diversity and Life Satisfaction, the Importance of Recreative Activities For Establishing and Strengthening These Relations", International Journal of Human Sciences, Vol.10, No. 1, pp 1078-1090.

[4] Sports Administration, Republic of China (Taiwan), Sports knowledge, http://www.sa.gov.tw, Accessed 1 July 2013.

[5] Hsieh, C.M. and Jeng, S.T., (2003) "The Relationships between Life Style, Leisure Motivation, and Leisure Participation among College Students in Taipei”, Journal of Taiwan Society For Sport Management, Vol. 2, No. 1, pp 50-65.

[6] Hung, W.C., (2001) Comparing Leisure Activity Participation among Junior College Students of Different Academic Achievements, Master Thesis if Chinese Culture University, Taiwan.

[7] Shieh, S.F. and Jeng, L.S., (1995) "A Study on Technical and Vocational College Students Status in Participating Leisure Activities”, Physical Education Journal, Vol. 20, No. 1, pp 123-134.

[8] Emeribe, V.C. and Akah, L.U., (2012) "Knowledge, Attitude and Participation of Male and Female Nurses in Recreational Activities in Cross River State, Nigeria", Canadian Social Science, Vol. 8, No. 4, pp 150-153.

[9] Lin, H.J., (2006), A Study of the Self-Determination Theory and Leisure-Sports Stages for the Female Teachers in Yunlin County, Master Thesis of National Chiayi University, Taiwan.

[10] Linstone, H.A. and Turoff, M. (1975) The Delphi Method: Techniques and Applications, Addison-Wesley.

[11] Hasanzadeh, M., Danehkar, A., and Pak, A., (2012) "Application of Delphi Method for Criteria Selection in Site Survey of Oil Jetties in Iran", Environment and Natural Resources Research, Vol. 2, No. 1, pp 119-128.

[12] Chang, J., (2004) "Study on the Issue of Taxation of E-Commerce Transaction: An Application of Delphi and AHP”, Journal of Business Administration, Vol. 60, No. 1, pp 85-114.

[13] Teng, J.Y., and Tzeng, G.H., (1989) "The Analytic Hierarchy Process: Concepts, Techniques and Applications (I)", Journal of the Chinese Statistical Association, Vol. 27, No. 6, pp 5-22.

[14] Teng, J.Y., and Tzeng, G.H., (1989) "The Analytic Hierarchy Process: Concepts, Techniques and Applications (II)", Journal of the Chinese Statistical Association, Vol. 27, No. 7, pp 1-20.

[15] Saaty, T.L., (1980) The analytic hierarchy process: Planning, Priority Setting and Resource Allocation, McGraw-Hill.

[16] Saaty, T.L., and Kearns, K.P., (1985) Analytic Planning- The Organization of Systems, International Series in Modern Applied Mathematics and Computer Science 7, Pergamon Press.

[17] Huang, H.C., (2013) "Weight Analysis of Criterion and Sub-Criterion for Supplier Selection", Journal of Next Generation Information Technology, Vol. 4, No. 5, pp 55-62.

[18] Mohammed F.A., and Hagag, M.A.E., (2013) "Integrating AHP and Genetic Algorithm Model Adopted for Personal Selection", International Journal of Engineering Trends and Technology, Vol. 6, No. 5, pp 247-256.

[19] Saaty, T.L. and Vargas, L.G., (1982) The Logic of Priorities, Kluwer-Nijhoff.

[20] Zakaria, N.F., Mohamed, H.D., and Razak, A.B., (2010) "Deriving Priority in AHP using Evolutionary Computing Approach", WSEAS transactions on information science and applications, Vol. 7, No.5, pp 714-724.

[21] Huizingh, E.K.R.E., and Vrolijk, H.C.J., (1995) Decision Support for Information Systems Management: Applying Analytic Hierarchy Process, Research Report No. 95B26, University of Groningen. 